\title{
DOÇURA E LABOR: UMA PRÁTICA PEDAGÓGICA COM FRAÇÕES NOS ANOS INICIAIS DO ENSINO FUNDAMENTAL
}

\author{
SWEETNESS AND LABOR: A PEDAGOGICAL PRACTICE WITH \\ FRACTIONS IN THE EARLY YEARS IN K-12 EDUCATION
}

\section{DULZURA Y LABOR: UNA PRÁCTICA PEDAGÓGICA CON FRACCIONES DURANTE LA EDUCACIÓN BÁSICA PRIMARIA}

\author{
Regina Maria Simões Puccinelli Tancredi ${ }^{\mathrm{I}}$ \\ Adriana Torquato Resende ${ }^{\text {II }}$
}

REsumo O objetivo deste artigo é analisar a prática pedagógica de uma professora do $5^{\circ}$. ano do Ensino Fundamental ao ensinar frações aos seus alunos. Para isso, foram realizadas com a professora e seus alunos entrevistas semiestruturadas ancoradas em roteiro prévio. A pesquisa desenvolveu-se numa escola pública de um município da Grande São Paulo. Os referenciais teóricos focaram o ensino reflexivo, o ensino de frações e a aprendizagem da docência, envolvendo autores como Arroyo, Marcelo, Mizukami e Shulman, entre outros. A pesquisa justifica-se porque as práticas pedagógicas são alguns dos modelos descritivos dos processos de ensino que podem contribuir para o aprimoramento profissional docente, quando socializadas. Essas práticas devem ser conhecidas e estudadas, favorecendo a troca de conhecimentos sistematizados e de experiências entre os pares. Os resultados evidenciaram a repercussão da prática pedagógica da professora na motivação dos alunos para aprender e aspectos da aprendizagem docente durante o processo de ensino.

Palavras-chave: Prática Pedagógica; Ensino de fração; Anos iniciais do ensino fundaMENTAL.

Universidade Federal de São Carlos (UFSCar), São Carlos/SP - Brasil

II Universidade Presbiteriana Mackenzie (UPM), São Paulo/SP - Brasil 
Abstract The aim of this article is to analyze a 5th-grade K-12 Math teacher's pedagogical practice when teaching fractions. To do so, were realized semi structured interviews with the teacher and students based in a previous script. The study took place in a public school from the metropolitan area of the city of São Paulo-Brazil. The theoretical background comes from the reflective teaching, the teaching of fractions and teacher's education and resorts to authors such as Arroyo, Marcelo, Mizukami and Shulman, among others. The research justifies itself because the pedagogical practices are some of the descriptive models of the teaching processes that can contribute for the teaching professional enhancement, when socialized. These practices should be know and studied, favoring the exchange of systematized knowledge and of experiences between peers. The results reveal that the teacher's pedagogical practice echoes both in the students' motivation to learn and in the teacher education itself during the teaching process.

Key-words: Pedagogical practice; Teaching of fractions; Early years in K-12 education.

Resumen El objetivo de este trabajo es analizar la práctica pedagógica de una profesora del $5^{\circ}$ año de la escuela primaria para enseñar fracciones a sus estudiantes. Para eso, se llevaron a cabo con la profesora y sus estudiantes entrevistas semiestructuradas basadas en guión previo. La investigación se desarrolló en una escuela pública en un municipio de Sao Paulo, Brasil. El marco teórico de referencia enfocó la enseñanza reflexiva, la enseñanza de fracciones y el aprendizaje de la docencia, apoyándose en autores como Arroyo, Marcelo, Mizukami, Shulman, entre otros. La investigación se justifica porque las prácticas pedagógicas son algunos de los modelos descriptivos de los procesos educativos que pueden contribuir al desarrollo profesional de los maestros, si socializado. Estas prácticas deben ser conocidas y estudiadas, lo que favorece el intercambio de conocimientos y experiencias sistematizadas entre pares. Los resultados evidenciaron la repercusión de la práctica pedagógica de la profesora en la motivación de los alumnos para aprender; y aspectos del aprendizaje docente durante el proceso de enseñanza.

Palabras clave: Práctica pedagógica; Enseñanza de fracción; Educación básica primaria.

\section{INTRODUÇÃo}

Este artigo tem como objetivo analisar uma prática desenvolvida por uma professora do $5^{\circ}$. ano do Ensino Fundamental ao ensinar frações aos seus alunos. Chamaremos essa professora de Sabrina (nome fictício).

A pesquisa foi realizada numa escola pública de um município da Grande São Paulo. Essa escola foi escolhida por ser bem conceituada na região, tendo obtido nota 5,7 no IDEB (Índice de Desenvolvimento da Educação Básica) em 2012, quando foi realizada a pesquisa. Na Prova Brasil, os resultados obtidos pelos alunos também foram superiores aos dos alunos de outras escolas da localidade, de acordo com os dados do site oficial da escola.

No ano de 2012, a escola atendeu a 1.229 alunos, oferecendo classes de $1^{\circ}$. ao $5^{\circ}$. ano do ensino fundamental, EJA (Educação de Jovens e Adultos) e Educação Especial para DA (Deficiente Auditivo). A maioria dos alunos era de classe média baixa. 
Para analisar a prática desenvolvida, foram feitas entrevistas semiestruturadas baseadas em roteiro prévio com a professora e 17 de seus alunos. Optamos por realizar a pesquisa com uma turma de $5^{\circ}$. ano do Ensino Fundamental em virtude da vivência dos alunos com o processo de escolarização e com práticas pedagógicas diversas. Esses alunos tiveram a participação na pesquisa autorizada por seus familiares.

Embora as entrevistas tivessem um roteiro com perguntas formuladas previamente, foram realizadas de maneira informal, com abertura para outras perguntas e participação espontânea dos entrevistados, conforme sugerido por Bogdan e Biklen (1994), quando afirmam que na investigação qualitativa os sujeitos devem expressar livremente suas opiniões sobre os assuntos pesquisados.

Durante as entrevistas, pedimos que os alunos descrevessem "uma aula muito legal". Dos 17 entrevistados, cinco (29,4\%) apontaram as aulas de Educação Física, principalmente por causa dos jogos coletivos (futebol, queimada). Logo em seguida veio a aula de Matemática, na qual a professora ensinou sobre frações utilizando barras de chocolate (quatro crianças; 23,5\%). As demais respostas se referiram às aulas de Inglês (três; 17,6\%); Artes (dois; 11,8\%); Geografia, Ciências e Informática (um aluno cada; 5,9\%).

Além da entrevista, pedimos que os alunos desenhassem uma aula que gostaram, com o objetivo de conhecer melhor suas perspectivas sobre assuntos lecionados e práticas pedagógicas desenvolvidas no contexto da sala de aula. À medida que os alunos entregavam os desenhos, pedíamos que explicassem o que retrataram.

Dos 17 desenhos feitos pelos alunos, sete mostravam a figura de um professor $(41,2 \%)$. Tendo as disciplinas ou as atividades como foco, contamos com cinco desenhos referentes à aula de Matemática; quatro relacionados à aula de Inglês; três à aula de Geografia; dois de Ciências; um de Língua Portuguesa; um de Educação Física e um de Libras. Assim, percebemos que a aula de Matemática era de fato uma das que mais chamavam a atenção desse grupo de alunos $(29,4 \%)$.

Consideramos importante a indicação da Matemática como uma aula interessante para os alunos, uma vez que de modo geral parece haver um distanciamento com relação a esses conteúdos à medida que a escolaridade avança, ou seja, nos primeiros anos do ensino fundamental os estudantes normalmente gostam de fazer matemática, mas com o passar dos anos da escolaridade essa aproximação parece que vai se esvaindo. Além disso, a Matemática continua a ser uma das disciplinas mais "temidas" do currículo, mesmo que atualmente, devido ao processo avaliativo existente nas escolas, ela não reprove mais os alunos, fazendo-os "repetir" o ano escolar.

Importa considerar, entretanto, que saber Matemática continua a ser uma das habilidades essenciais para a vivência no mundo tecnológico dos nossos dias, no qual ela se insere de inúmeras maneiras complexas. Considerando apenas seu valor no cotidiano, poucas são as situações em que noções matemáticas ou a elas relacionadas estejam ausentes, seja de maneira intuitiva, como no caso de atravessarmos uma rua sem sermos atropelados, seja em sua natureza mais formal, quando importa analisarmos as situações que afetam o orçamento familiar. 
Levando em conta esse fato e a menção de que a professora Sabrina ensinara sobre frações utilizando barras de chocolate, sentimos a necessidade de conhecer melhor sua prática no desenvolvimento desse componente curricular e, mais especificamente, o que acontecera durante a aula de frações.

Embora não se trate de uma ideia original ou inovadora, as crianças manifestaram especial apreço por essa aula. Ao que parece, a doçura do chocolate e o labor da professora ao prepará-la e desenvolvê-la fizeram que a experiência de aprender frações se tornasse significativa para aqueles alunos.

Em virtude dessas circunstâncias, trazemos neste texto uma discussão sobre a aprendizagem inicial de frações por alunos do $5^{\circ}$. ano e os caminhos percorridos pela professora para ensinar a respeito do tema, explicitados por ela em entrevista. Autores como Arroyo (2010), Corradini e Mizukami (2011), Marcelo (1999), Nunes e Bryant (1997), Shulman (2014) e outros compõem o referencial teórico que apoiou a pesquisa.

Entendendo o ensino de frações como um processo complexo que exige dos professores o desenvolvimento de estratégias que facilitem o entendimento do conteúdo em questão pelos alunos, o foco deste artigo está nas ações da professora, pois a prática docente pode ser compreendida como "espaço mais importante, permanente e efetivo de formação docente" (MIZUKAMI et al., 2010, p. 40).

As análises foram efetuadas sob a perspectiva de teorias sobre ensino reflexivo e aprendizagem da docência, a qual se dá, entre outras formas, pela divulgação, estudo e sistematização de práticas produzidas pelos professores em serviço.

\section{Prática Pedagógica e ensino Reflexivo}

Práticas pedagógicas são compreendidas neste artigo como "a descrição do cotidiano do professor na preparação e execução de seu ensino" (CUNHA, 1989, p. 105). Numa perspectiva interpretativa, que considera a construção social da realidade, essas práticas são resultantes de interações entre as teorias e as vivências dos professores (CALDEIRA e ZAIDAN, 2010).

Em oposição à perspectiva positivista, que pressupõe a elaboração de teorias educativas que devem ser aplicadas na prática de acordo com critérios de eficiência cientificamente comprovados, a abordagem interpretativa considera teoria e prática como processos complementares. Nas palavras de Caldeira e Zaidan (2010, p. 2):

\footnotetext{
Nessa visão, a prática se modifica mudando a maneira de compreendê-la. Essa nova compreensão da prática possibilita que o indivíduo reconsidere crenças e atitudes inerentes à sua maneira de pensar atual, sendo capaz de exercer uma influência prática. Assim, a relação teoria-prática é entendida como uma troca bidirecional: a deliberação prática está informada não só pelas ideias, mas também pelas exigências práticas de cada situação, uma vez que o juízo crítico e a mediação do critério do ator são sempre indispensáveis.
} 
Assim, o trabalho docente pode ser considerado ao mesmo tempo teórico e prático. A definição do professor como um "prático reflexivo" (MARCELO, 1999, p. 131) parece apropriada, uma vez que cada professor descobre seu modo pessoal de ensinar, o que, entretanto, não se dá em detrimento dos conhecimentos teóricos. O conceito de prática reflexiva valoriza a experiência e estimula a autoavaliação dos docentes, sem prescindir de seus conhecimentos, tanto dos específicos como dos pedagógicos e de outros de diferentes naturezas (SHULMAN, 1986).

De acordo com Corradini e Mizukami (2011, p. 54), “os professores que são práticos reflexivos desempenham notáveis papéis na produção de conhecimento no ensino", uma vez que cada professor tem conhecimentos e características próprias e "a reflexão implica intuição, emoção, paixão", não sendo "um conjunto de técnicas que possa ser [diretamente] ensinado".

Discorrendo acerca do conceito de reflexão-na-ação de Schön, as autoras explicam que os professores constroem seus conhecimentos "servindo-se de diferentes fontes, inclusive a da prática profissional” (CORRADINI; MIZUKAMI, 2011, p. 55), uma vez que a docência "é uma profissão em que a própria prática conduz necessariamente à criação de um conhecimento específico ligado à ação" (p. 56). Isso ocorre porque os alunos respondem às ações dos professores de modo positivo ou negativo, e essas respostas parecem influenciar as práticas docentes.

Dessa forma, os professores em exercício são produtores de conhecimento sobre o ensino e compreendê-los assim pode contribuir para o desenvolvimento profissional docente, uma vez que esse posicionamento valoriza e reconhece suas práticas pedagógicas desenvolvidas em sala de aula (MIZUKAMI et al., 2010). Ao mesmo tempo, a divulgação dessas práticas pode ser útil para que docentes desenvolvam um ensino mais contextualizado e apropriado às características discentes.

Com base nas ideias de Dewey, Corradini e Mizukami (2011) afirmam que os professores devem desenvolver três atitudes para promover um ensino reflexivo: ter a mente aberta para novas ideias, ser intelectualmente responsável por seus posicionamentos práticos e teóricos e estar disposto a trabalhar com entusiasmo, curiosidade e energia. A reflexão antes, durante e depois da prática pedagógica pode, assim, favorecer a aprendizagem dos alunos e também - e principalmente - a dos professores, constituindo-se, ao lado do conhecimento do conteúdo a ser ensinado e de diferentes formas de fazê-lo, um elemento essencial da base de conhecimento dos professores para o ensino (WILSON, SHULMAN e RICHERT, 1987).

Quanto ao ensino reflexivo, temos a afirmação de que:

....apesar da diversidade teórica e metodológica com que é abordado, o 'ensino reflexivo' aglutina as preocupações com a experiência pessoal e com a prática na formação e no desenvolvimento profissional de professores. A premissa básica do ensino reflexivo considera que as crenças, os valores e as hipóteses que os professores têm sobre o ensino, a matéria que lecionam, o conteúdo curricular, os alunos e a aprendizagem estão na base de sua prática de sala de aula. A 
reflexão oferece a esses professores a oportunidade de se tornarem conscientes de suas crenças e hipóteses subjacentes a suas práticas, possibilitando, assim, o exame de validade de tais práticas na obtenção das metas estabelecidas (MIZUKAMI et al., 2010, p. 49).

As autoras destacam a necessidade de se repensar a prática, tendo em vista a aprendizagem de um grupo específico de alunos. Nesse sentido, o professor reflexivo cria novas oportunidades de aprendizagem mediante a análise e a avaliação do que acontece em sua sala de aula. Observando as reações dos alunos, ele pode elaborar novas estratégias de ensino que promovam uma aprendizagem contextualizada e que tenham significado para os estudantes.

Considerando o espaço escolar como ambiente de aprendizagem dos professores, Corradini e Mizukami (2011) destacam a importância do desenvolvimento de um "ambiente convidativo" na escola, o qual pode promover o crescimento social e intelectual de todos os que nela trabalham e convivem. Para elas, "uma escola convidativa e acolhedora tem as seguintes características: o respeito à singularidade do indivíduo, o espírito colaborativo, o sentido de pertencer, o ambiente agradável e as expectativas positivas" (p. 59).

Tendo em mente esses aspectos, importa voltar o olhar para a prática da professora Sabrina ao ensinar sobre frações, um dos conhecimentos que os alunos do $5^{\circ}$. ano devem aprender na escola.

\section{FraÇão de ChOCOLATE: UMA PRÁtiCA PEDAGóGiCA EM FOCO}

De acordo com os Parâmetros Curriculares Nacionais de Matemática para os anos iniciais do ensino fundamental, no segundo ciclo dos anos iniciais ( $4^{\circ}$. e $5^{\circ}$. ano) os alunos devem ampliar seus conhecimentos sobre os números, construindo "o significado do número racional e de suas representações (fracionária e decimal), a partir de seus diferentes usos no contexto social" (BRASIL, 2000, p.80). Além disso, precisam "interpretar e produzir escritas numéricas, considerando as regras do sistema de numeração decimal", bem como "resolver problemas (...) em situações que envolvam números naturais e, em alguns casos, racionais" (IDEM, p. 80).

Conforme descrito nos Parâmetros Curriculares Nacionais de Matemática:

\footnotetext{
Neste ciclo são apresentados aos alunos situações-problema cujas soluções não se encontram no campo dos números naturais, possibilitando assim, que eles se aproximem da noção de número racional, pela compreensão de alguns de seus significados (quociente, parte-todo, razão) e de suas representações, fracionárias e decimal (BRASIL, 2000, p. 83).
}

Além disso, eles devem "explorar diversos significados das frações em situações-problema: parte-todo, quociente e razão" (IDEM, p. 86). A relação parte-todo é, entre as três ideias citadas, a que está mais presente nas aulas de Matemática, especialmente nos anos iniciais, e um dos motivos dessa prioridade pode ser o fato de que mesmo os professores não têm clareza sobre os diversos significados presentes no traço fracionário. Assim, a ideia

Comunicações | Piracicaba | v. 24 | n. 2 | p. 181-198| maio-agosto 2017 
que muitos professores e alunos dos anos iniciais têm a respeito de fração vincula-se à sua representação $\mathrm{a} / \mathrm{b}$ com $\mathrm{a}, \mathrm{b}$ inteiros e $\mathrm{b} \neq 0$ : alunos e professores contam o total das partes de um todo contínuo e as partes "pintadas"/“comidas", no caso do chocolate ou sua representação nos cadernos (uma superfície, de todo o jeito), indicando-as convenientemente, sem entenderem o significado nessa nova notação. Confirma-se, com relação ao ensino de fração, que tem havido, ao longo do tempo, uma ênfase forte nos procedimentos, deixando em segundo plano o que se esconde por detrás deles. Para a aprendizagem da Matemática, essa tendência é prejudicial, pois não dá aos alunos ferramentas para pensar.

Por sua vez, o conceito de fração tem suas "sutilezas" e, embora haja uma tendência a associá-lo a contextos próximos ao dia a dia dos alunos, nem sempre é adequado fazê-lo. Isso porque uma das exigências fundamentais do conceito é de que o inteiro seja dividido em partes exatamente iguais e no cotidiano, às vezes, nos defrontamos - como no dizer de alunos menores, com a "metade maior" e a "metade menor". Esse mesmo referencial (as partes iguais) pode não estar presente quando os alunos representam nos seus cadernos, por cópia da lousa ou de livros, ou por sugestão dos professores em alguma atividade específica, um inteiro dividido "à mão livre" em "partes iguais".

Maior complexidade ainda existe quando buscamos representar partes iguais de inteiros que representam círculos ou formas geométricas diferentes das do quadrado e do retângulo. No caso do círculo em papel, destacamos que se trata de fração de uma área (portanto contínua, inumerável), muito diferente conceitualmente da fração de uma quantidade discreta de objetos (numerável). No caso específico, a dificuldade é menor quando utilizamos as metades, como $1 / 2$ (dobrando-o em duas partes iguais, pelo diâmetro), ou metades de metades como $1 / 4$ (dobrando as primeiras metades pela metade agora usando o raio) e assim sucessivamente 1/8, 1/16 etc., até o material concreto permitir. Ou seja, o número de dobras possíveis de serem representativas dessas frações depende um pouco do tamanho do papel para que guardem proporcionalidade entre si. Já representar no círculo de papel frações como $1 / 3,1 / 5,1 / 6$ e assim por diante, envolve cálculo de ângulos para que sejam partes iguais da área, os quais podem ser bem representados com uso de instrumentos como compasso e transferidor, sendo utilizados por alunos maiores, associando o desenho com a geometria.

No caso do chocolate, não se trata mais de fração de área, mas de volume, ou até mesmo de peso. Por isso, apesar do chocolate real estar aparentemente dividido em partes iguais, não se garante efetivamente que o esteja.

Isso posto, Lima (1993, p. 82) alerta para o risco de "a criança não ter adquirido ainda a conservação de quantidade contínua (área, comprimento etc.)" e de não saber como reconstituir o todo que foi dividido em partes iguais, o que é também uma característica presente no conceito de fração. $\mathrm{O}$ autor esclarece que a conservação de quantidade é aquela relacionada ao fato de "que a quantidade (contínua ou discreta) permanece invariável, enquanto outros aspectos (forma, posição etc.) se modificam" (p. 82).

Pode-se argumentar que é importante aprender a ideia geral de fração como parte de um todo e que dividir chocolates e pizzas pode ser indicado para iniciar as crianças nos estudos sobre frações, por serem alimentos que em geral as agradam. Não há como negar que 
a associação com atividades e prazeres do dia a dia possa ser um caminho para aproximar os alunos de conceitos abstratos como o são os da Matemática. O problema é não ir além e ficar na atividade empírica, deixando encobertos os significados dos temas em questão.

Importa destacar, ainda, que a Matemática não é um conjunto arbitrário de regras e sim uma forma lógica de pensar sobre noções abstratas, que não existem de maneira real no cotidiano, qualquer que seja o significado que atribuímos ao termo cotidiano. Além disso, essas formas de pensar são socializadas por meio de um código não universal, visto que cada grupo social pode estabelecer suas próprias representações das ideias, ainda que o desenvolvimento da humanidade tenha adotado mais amplamente alguns padrões do que outros, como é o caso muito "simples" do sistema de numeração decimal.

O papel da escola, no que tange à aprendizagem da Matemática e sua linguagem, é a de possibilitar aos alunos certo tipo de conhecimento e de raciocínio que lhe permitam participar melhor do mundo social. Ora, Nunes e Bryant (1997, p. 27) consideram que:

...qualquer coisa em matemática que poderia ser chamada de uma 'invenção cultural' pode apenas ser entendida por alguma forma de transmissão cultural. Mas aprender a usar estas ferramentas culturais não é tão simples como pode parecer à primeira vista.

Assim, não podemos garantir que usar pizzas ou chocolates para ensinar sobre frações possa ser um diferenciador significativo na aprendizagem dos alunos, pois além de culturalmente não dividirmos esses alimentos em partes iguais, estes podem não estar presentes nos hábitos alimentares de muitas das famílias brasileiras, por diversos motivos. Entretanto, na escola a prática de associar partes de um alimento com frações não é incomum e o relato dos entrevistados dessa pesquisa e de sua professora vai nessa direção.

A professora justificou sua escolha de introduzir o ensino sobre frações por meio da divisão (pretensamente em partes iguais) de um chocolate, por meio do qual buscava avançar utilizando o "concreto" e não uma figura dele representativa:

Eu olhei nos livros didáticos, neles havia muitos desenhos de chocolate e de pizza. Então pensei: por que não fazer com o chocolate mesmo? Como a sala é muito heterogênea (no início do ano ainda havia cinco crianças pré-silábicas) e o conteúdo é muito abstrato, resolvi trabalhar com os chocolates (SABRINA, 2012).

Percebemos que a professora, antes de iniciar o ensino de um assunto novo para os alunos, procura orientações nos livros didáticos, o que revela sua preocupação em adotar procedimentos adequados para a aprendizagem dos alunos, ainda mais considerando a característica do conteúdo que pretende desenvolver (abstrato).

Louve-se o empenho dessa profissional, pois para ela a Matemática não foi uma disciplina de que particularmente gostava ou que tenha aprendido o suficiente para ensinar. Seu perfil revela uma dificuldade que o sistema educacional atual está enfrentando: a falta de professores qualificados para o ensino. 
Eu sou formada em Letras. Não sou muito fã de Matemática. Mas parto do conceito de que não é porque eu não gosto que os outros não vão gostar. Sempre que vou ensinar algo novo, eu pesquiso e pergunto para outros professores. Quando eu era criança eu tive dificuldade em Matemática (SABRINA, 2012).

A professora reconhece suas limitações, mas tem interesse de que seus alunos aprendam e para isso procura estratégias que considera interessantes para eles. Entretanto, sem uma boa base conceitual (conhecimento do conteúdo específico; WILSON, SHULMAN e RICHERT, 1987) é difícil diversificar adequadamente a prática. Por isso, ela se apoia nos livros e nos pares, o que revela uma característica da aprendizagem docente: a aprendizagem na ação e na escola, com os pares.

Sabrina (2012) revela como introduziu o assunto: "Eles nunca tinham tido fração. Comecei a aula com uma conversa [...]. Perguntei o que eles sabiam a respeito disso, o que achavam que seria. Fui elogiando e consertando (sic) alguns conceitos errados".

Não foi possível, durante a entrevista, saber quais eram os conceitos errados e como a professora interveio para corrigi-los. É importante salientar que antes de decidir utilizar o chocolate para ensinar frações, a professora verificou que não havia alunos diabéticos nem alérgicos em sua classe.

Ela continua seu relato: "Marcamos um dia para trazer os chocolates e todos trouxeram. Não mandei comprar chocolates iguais, porque as coisas são diferentes. Eu pedi para que cada um trouxesse uma barra de chocolate sem recheio e que fosse dividida em quadradinhos" (SABRINA, 2012).

Então, começou o trabalho com os chocolates trazidos pelos alunos: "Coloquei o conceito na lousa. Mostrei como a gente fazia... numerador, denominador. A parte de cima era a parte que a gente tirava" (SABRINA, 2012).

E o que significava a "parte de baixo"? Na verdade, essa "parte" é a ideia mais importante numa fração, pois define em quantas partes o chocolate (ou o inteiro) estava dividido, sem considerar o espaço que possivelmente existia em seus "pedaços". Dado o contexto da atividade, podemos supor que isso era irrelevante nesse primeiro momento.

\footnotetext{
Aí eu pedi que abrissem o chocolate e deixassem em cima da mesa. Cada um tinha que contar quantos quadradinhos tinha o seu chocolate. Eu perguntei a cada um em quantas partes foi dividido o seu chocolate. Então perguntei o que seria o chocolate todo e concluímos que era "inteiro". Eu ia perguntando e colocando na lousa (SABRINA, 2012).
}

Não sabemos o que foi colocado na lousa, pois a entrevista ocorreu posteriormente à aula, mas seria desejável que houvesse representações como $2 / 2,4 / 4,8 / 8$, entre outras possíveis, que representam o inteiro. Os desenhos de alguns alunos, apresentados a seguir, podem nos dar uma ideia. 


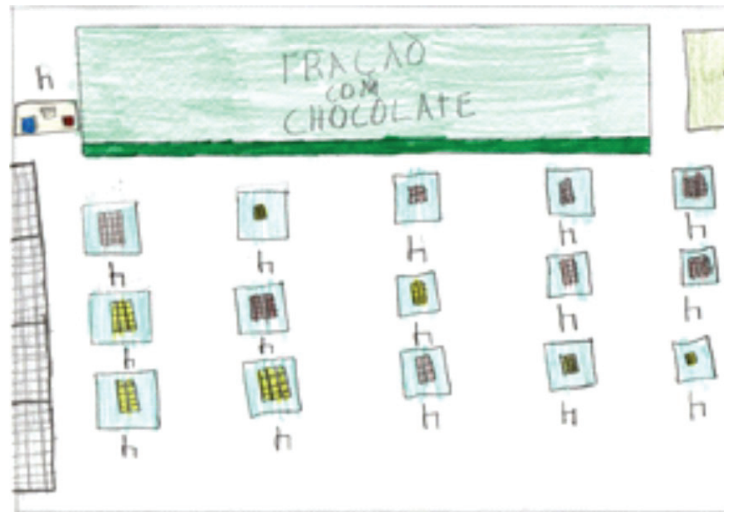

Figura 1: representação da aula de matemática

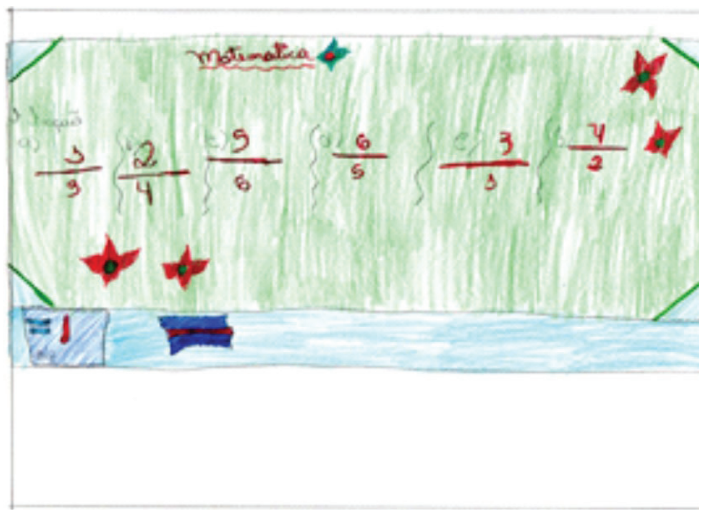

Figura 2: desenho da lousa na aula de frações

Na Figura 1, percebemos as diferentes divisões do chocolate, o que poderia ter proporcionado uma discussão rica, pois aparece claramente que os desenhos foram feitos à mão livre e as partes não são iguais, embora sirvam ao propósito inicial de uma aula sobre frações; já, na Figura 2, observamos frações que são maiores do que o inteiro, como 6/5, $3 / 1,4 / 2$ e parecem fora do contexto da aula que analisamos. Entretanto, mostram o tipo de notação que a aluna aprendeu, embora não revelem se o conceito foi apropriado.

Sabrina (2012) prossegue:

Então pedi para cada um desenhar o seu chocolate no caderno. Depois eu disse que teriam que fazer algo muito difícil. Eles ficaram ansiosos... Eu disse para cada um comer um quadradinho (não necessariamente um quadrado...) do seu chocolate. E aí perguntei: Continua sendo um chocolate inteiro? Dá pra representar algo que não é mais inteiro? Como? Que fração eu vou ter? E eles foram representando o que tinham comido. Aí expliquei como se lia: um quarto, por exemplo. E disse que a partir do décimo primeiro acrescentava a palavra "avos": um doze avos.

A professora, embora tenha pedido desenhos do chocolate, acertadamente pediu o registro da representação fracionária:

$\mathrm{Na}$ aula, tudo eles tinham que registrar. (...) Primeiro eles desenharam e pintaram todo o chocolate. Depois, desenhava o chocolate de novo, mas só pintava a parte que comeu. Pedi para eles comerem mais um quadradinho e representar no caderno. Depois deram um quadradinho para o colega (SABRINA, 2012).

Observe-se que ao dar as orientações a professora desconsiderou o desenho que eles fizeram, pois a cada desenho a área desenhada possivelmente era outra e poderia não manter a mesma relação de igualdade. Só para usar o exemplo em pauta: $1 / 2$ de um chocolate grande não representa a mesma quantidade que $1 / 2$ de um pequeno. Parece claro que a professora não queria comparar frações, mas será que estava atenta para esses detalhes? 
Para ampliar a associação do chocolate comido com a fração, a professora expandiu a experiência para além da sala de aula: "Depois levaram para alguém fora da sala (colega, funcionário ou professores). Tudo eles iam registrando". Com isso, ela conseguiu o reconhecimento da diretora da escola e a disseminação de sua prática, que foi socializada entre os colegas: "Eles [os alunos] gostaram tanto que a diretora pediu para eu passar para os outros colegas e todos os quintos anos fizeram o mesmo" (SABRINA, 2012).

Nesse dia, Sabrina não se preocupou com o tempo gasto na atividade, ocupando três aulas. Todo o seu empenho despertou o interesse dos alunos e o resultado foi que dos seis que a professora indicou terem dificuldade, três compreenderam de maneira satisfatória o conteúdo ensinado, segundo seus relatos.

A professora, afinal, percebeu o resultado de sua ação e refletiu sobre ela, tomando decisões para a continuidade do estudo sobre frações: "Os meus alunos gostaram tanto que queriam fazer com pizza. Achei que ia ser complicado e então fizemos com pizza de papel" (SABRINA, 2012).

Acertada decisão, pois ao trabalhar a "pizza" de papel, cada aluno pode dobrá-la facilmente em partes iguais (2, 4, 8 e seus múltiplos) e assim obter partes efetivamente fracionárias. Sua disposição para ajudar as crianças a compreenderem a ideia (intuitiva) de fração (não dizemos o conceito!) merece destaque. Entretanto, é preciso muito cuidado com o ensino dessa noção, pois Nunes e Bryant (1997) nos alertam que:

Com as frações as aparências enganam. Às vezes as crianças parecem ter uma
compreensão completa das frações e ainda não a têm. Elas usam os termos
fracionários certos; falam sobre frações coerentemente, resolvem alguns pro-
blemas fracionais; mas diversos aspectos cruciais das frações ainda lhes esca-
pam. De fato, as aparências podem ser tão enganosas que é possível que alguns
alunos passem pela escola sem dominar as dificuldades das frações, e sem que
ninguém perceba (p. 191).

No caso das crianças entrevistadas, elas demonstraram especial apreciação pelas aulas de Matemática nas quais a professora regente da turma ensinou fração utilizando barras de chocolate e isso, muito provavelmente, trouxe para a profissional novos conhecimentos sobre o ensino de frações e, em decorrência, para o ensino de outros conteúdos, matemáticos ou não.

Um problema, no caso que estamos analisando, é que Guskey (apud MARCELO, 1999, p. 48) afirma que os professores mudam suas crenças e atitudes quando percebem "resultados positivos na aprendizagem dos alunos". A professora, ao contrário, pode ter reafirmado sua crença de que a estratégia escolhida para o ensino de fração foi correta e que seus alunos aprenderam o conceito. O que não é, absolutamente, possível afirmar sem sabermos mais sobre o que a professora sabe a respeito do tema e o que seus alunos efetivamente foram capazes de abstrair.

A experiência com frações realizada pela professora junto ao seu grupo de alunos do $5^{\circ}$. ano revelou que a aprendizagem docente ocorreu também durante o processo de ensino e repercutiu na aprendizagem dos alunos e em sua motivação para aprender. 
Assim, ser sensível ao outro - no caso o professor ser sensível aos interesses e necessidades de seus alunos - faz parte da tarefa docente e isso parece uma característica dessa professora, que busca alternativas para o ensino, sem deixar de lado os conhecimentos conceituais.

Analisando o relato da professora sobre a aula com frações e as manifestações dos alunos, foi possível perceber que o sucesso se deu em função das seguintes ações propostas por ela e desenvolvidas pelas crianças:

- trazer um objeto comestível e saboroso para a escola (a barra de chocolate);

- ter a liberdade de escolher o chocolate de sua preferência, com a condição de ser em barra e sem recheio;

- comer o chocolate durante a aula;

- desenhar a barra de chocolate inteira e depois de cada modificação efetuada na mesma;

- refletir e dialogar acerca das diferenças entre as barras de chocolate e as maneiras de descrever seu fracionamento em linguagem matemática;

- identificar o conceito de fração num objeto concreto (a barra de chocolate e suas partes);

- compartilhar seu chocolate com um amigo e provar o chocolate do amigo;

- doar um pedaço do seu chocolate para uma pessoa da escola, fora de sua classe;

- socializar o conhecimento adquirido em aula com colegas de outra classe, com professores e outros trabalhadores da escola.

Entretanto, convém salientar que os conceitos fundamentais da Matemática, que são desenvolvidos junto aos alunos dos anos iniciais do ensino fundamental, não são tão simples como parecem.

Pelos relatos dos participantes da pesquisa, soubemos que a professora também propôs atividades interativas extraclasse em outras aulas, como na de Geografia, na qual os alunos entrevistaram pessoas da escola para descobrir suas regiões de origem, reforçando o conceito de regiões e aprendendo a localizá-las no mapa. Nessa aula, houve envolvimento e interação entre alunos e professores de outras classes e com outros educadores da escola. Segundo Arroyo (2010, p. 159):

A mente das crianças já é ativa, enfrenta situações diversas e nesse enfrentar se forma e estimula. Dialoga, imita e na interação com os outros, na produção coletiva se estimula e se forma. Os processos cognitivos são mais ativos do que receptivos, mais interativos do que solitários. Teríamos de captar a importância da interação nos processos de aprendizagem e desenvolvimento. Captar nosso papel de mediadores, estimuladores de interações ativas. Uma arte que faz parte de nosso ofício e que muitos educadores praticam com tanta habilidade.

Para Arroyo (2010), atividades que extrapolam a sala de aula e promovem interações diferenciadas podem modificar a cultura escolar e a cultura profissional docente, tornando os professores "mediadores e estimuladores de interações" (p. 159). 
Em síntese, ao introduzir o assunto sobre fração por meio de um chocolate dividido, desde a fábrica, em partes iguais, Sabrina parece ter conseguido que os alunos se aproximassem do conceito de fração e se sentissem empoderados ao socializarem seu novo conhecimento. Além disso, a experiência pode ter ajudado a professora a se projetar entre seus pares, potencializando seu interesse em adaptar à realidade de seus alunos estratégias indicadas como corretas em materiais didáticos. Mais do que isso, a professora conseguiu aprender com a prática, refletiu sobre ela e pode ter se tornado reflexiva, analisando possibilidades de ensino.

Assim, parece-nos que durante o trabalho com frações realizado nessa classe de $5^{\circ}$. ano, parafraseando Romanatto e Tancredi (2013, p. 101), diversas linguagens foram interligadas em uma extensa rede de comunicação para a compreensão desse conceito matemático, e isso teve um papel importante na aprendizagem dos alunos. Para esses autores, "a simbologia universal da Matemática serve como elaboração da objetividade, mas sua aprendizagem requer essa articulação com outras formas de comunicação; língua falada ou escrita, ícones, desenhos" (p. 101-102).

Continuando seu raciocínio, Romanatto e Tancredi (2013) afirmam, apoiando-se em Pais (2006), que os redatores de textos escolares precisam dar mais atenção aos aspectos didáticos no ensino de Matemática, "para o sentido das instruções de enunciado dos problemas, proposições e observações complementares, cuja redação deve ser suficientemente clara, a fim de minimizar o conflito de interpretações ambíguas" (p. 102).

Acrescentamos que devem ter mais atenção ao sugerir estratégias para a abordagem dos temas matemáticos, esclarecendo a fundo os conceitos que as apoiam. Não é possível presumir que todos os professores que usam esses materiais como apoio tenham os conhecimentos específicos necessários para bem utilizá-los.

\section{Concluindo O TEXTo}

Neste artigo trouxemos um exemplo concreto de prática pedagógica de uma professora de $5^{\circ}$. ano do ensino fundamental, profissional essa com formação específica em curso de licenciatura em Letras e que concluiu a Pedagogia enquanto atuava junto a classes de crianças de 6 anos a 10 anos de idade.

Arroyo (2010) analisa essa realidade de formar-se enquanto em atuação:

Pensemos em um fato tão conhecido, alunos e alunas das escolas normais e dos cursos de licenciatura e pedagogia estudam e trabalham. Por vezes, essa trajetória vem desde a Educação Fundamental. [...] Sabemos como essa condição afeta as possibilidades de dedicação ao estudo, de tempos livres, de contato com a cultura acadêmica e extra-acadêmica... Tem sido destacado como essa realidade afeta o nível dos cursos, o preparo dos mestres, sem dúvida, porém, o que pretendo destacar é que essa condição social, essa vivência de trabalho e estudo, condiciona a própria autoimagem de professor(a) e do magistério (p. 127).

No caso analisado, a professora produziu conhecimentos sobre o ensino, na ação cotidiana, o que referenda a literatura acerca da aprendizagem docente, que ocorre ao longo da 
vida e vem de diferentes fontes, no caso os manuais disponíveis para a sua consulta. Esses professores transformam os conhecimentos adquiridos dessas fontes para que se tornem adequados ao grupo de alunos em que atuam. Ou seja, eles transformam o conhecimento dos livros em conhecimentos ensináveis, avaliam sua prática e a reafirmam ou modificam, conforme o processo de raciocínio pedagógico definido por Shulman (2014).

Não temos a pretensão de concordar integralmente com a prática desenvolvida, mas consideramos que casos "bem-sucedidos", que aproximam as crianças dos conceitos matemáticos abstratos devem ser divulgados de forma a valorizarmos os docentes que assumem efetivamente sua tarefa, embora com as limitações indicadas. Consideramos que não são poucos esses docentes que procuram ir além do seu conhecimento, ainda que, muitas vezes, as críticas às suas práticas sejam mais frequentes do que os elogios.

O estudo e a divulgação de casos reais, de histórias verdadeiras acerca dos docentes e de seu trabalho podem trazer uma contribuição significativa para os professores em atuação e também para os futuros professores, ainda nos cursos de formação. Segundo Marcelo (1999, p. 155), “o conhecimento de casos é um conhecimento fundamentalmente ligado à ação, na medida em que emerge de e se relaciona com personagens e situações vividas pelo professor de forma particular".

Os casos, bem como a análise de biografias, podem ser utilizados como elementos de reflexão e de modificação da ação e das teorias dos professores. Uma aula que "deu certo" pode servir de inspiração e até de modelo, contanto que adaptada às necessidades e à realidade de cada turma.

Como temos, no caso da prática ora relatada, apenas as opiniões dos alunos e da professora, convém lembrarmos o que diz Shulman (1986, p. 9):

\footnotetext{
Professores devem não apenas ser capazes de definir para os estudantes as verdades aceitas em um domínio do conhecimento. Eles devem ser capazes de explicar porque uma proposição particular é considerada verdadeira, porque vale a pena conhecê-la e como ela se relaciona a outras proposições, tanto no âmbito da mesma disciplina como em outras, tanto na teoria como na prática (tradução livre).
}

Ou seja, a prática docente intuitiva, revelada no caso do ensino de frações, seria mais propícia à aprendizagem docente e à análise de outras situações similares se os professores conhecessem melhor os conteúdos que precisam ensinar aos seus alunos, desde como foram historicamente construídos, passando pela aplicabilidade deles no desenvolvimento da humanidade, na vida em sociedade de cada um e na possibilidade de construção de novos conhecimentos em diferentes áreas. Uma nova dimensão seria então dada ao conhecimento escolar e, pode-se supor, a escola seria revalorizada pelos alunos.

Entretanto, o conhecimento dos componentes curriculares é necessário, mas não é o suficiente para fazer a transposição de conhecimentos específicos para o ensino. É importante que os professores desenvolvam outros tipos de conhecimento, entre os quais os conhecimentos pedagógicos, o conhecimento do currículo, dos alunos, do contexto, de 
casos, entre outros (MIZUKAMI, 2004). Assim, desenvolveriam com mais segurança o conhecimento pedagógico do conteúdo, que é construído pelo professor como resultado da fusão de seus conhecimentos específicos sobre a matéria a ser ensinada e os conhecimentos pedagógicos. O conhecimento pedagógico do conteúdo envolve "as proposições teóricas, que são potencialmente as armas mais poderosas que os professores podem ter" (SHULMAN, 1986, p. 12; tradução livre), e a "sabedoria da prática" (SHULMAN, 2014, p. 211), construída no cotidiano escolar.

Abud (2001, apud SILVA et al., 2007), por sua vez, esclarece que, além da forma como os conteúdos são ensinados, as qualidades pessoais dos docentes também influenciam no processo de aprendizagem do aluno. Empatia, atenção, desejo de que o aluno seja bem-sucedido, disposição e persistência são fatores que facilitam as interações professor-aluno e, consequentemente, a aprendizagem. Podemos dizer que essas características pessoais e profissionais estão presentes no conhecimento pedagógico do conteúdo dos professores, visto ser a docência uma profissão pautada nas relações interpessoais.

No caso da professora entrevistada, os aspectos citados foram evidenciados pelos depoimentos das crianças nas entrevistas. Elas mostraram apreço pela escola, pelas aulas e pela professora. Ela foi elogiada por vários alunos, especialmente por explicar bem a matéria, como pode ser verificado em suas afirmações:

\footnotetext{
A professora explica direitinho, ela explica mesmo que você não entende, até você entender.

Quando um aluno não entende ela explica de novo. Quando um aluno faz coisa errada, ela vai e corrige ele.

Ela é legal, não briga com a gente, passa lição e quer que a gente entende (sic.). Ela ensina bem, explica bem os trabalhos, as provas... ela fala o que tem que fazer (ALUNOS DO 5 ${ }^{\circ}$. ANO, 2012).
}

Cunha (1989) também aponta a habilidade de formular perguntas, o estímulo à participação dos alunos, a utilização de "palavras de reforço" (p. 141), a variação de estímulos e um profundo conhecimento do conteúdo como características de bons professores. Embora a autora tenha evidenciado a relação afetiva do professor com sua matéria de ensino como elemento importante da prática docente, a professora que entrevistamos afirmou não gostar muito de Matemática. Mesmo assim, foi capaz de executar um bom trabalho, o que nos leva a inferir que os aspectos cognitivos sobrepujaram os de relacionamento com a matéria, tendo em vista a importância que atribuiu à aprendizagem matemática dos alunos.

Essa realidade reafirma a importância de socializar práticas pedagógicas que, embora simples, podem ser consideradas bem-sucedidas. O conhecimento das histórias dos professores, as descrições de suas crenças, suas narrativas, são alguns dos modelos descritivos dos processos de ensino que podem contribuir para o aprimoramento das práticas docentes.

A professora entrevistada desenvolveu algumas ações que produziram resultados satisfatórios no contexto específico daquela sala de aula: pesquisar o assunto a ser ensinado, perguntar aos colegas, conversar com os alunos sobre o tema, fazer perguntas aos alunos, 
elogiar as respostas corretas e corrigir os equívocos, expor o conteúdo, pedir que os alunos registrassem por escrito e por meio de desenhos aquilo que estavam aprendendo, entre outras estratégias. Ou seja, um professor precisa conhecer "150 maneiras de ensinar", como afirma o título e o corpo do artigo de Wilson, Shulman e Richert (1987).

A prática desenvolvida por Sabrina, ao ensinar frações para os seus alunos, foi considerada bem-sucedida em seu contexto de trabalho, não somente pelas crianças, mas também pelas diretoras da escola e demais professoras.

Podemos afirmar que a professora Sabrina produziu um conhecimento no ensino, ligado à sua opção metodológica e sua ação, em função dos resultados que suas escolhas iniciais tiveram sobre seus alunos. Parece-nos que ela havia desenvolvido as atitudes apontadas por Corradini e Mizukami (2011) para promover o ensino reflexivo: aceitou novas ideias para ensinar frações, responsabilizou-se por suas escolhas e teve empenho e energia para ajudar seus alunos a aprenderem. Além disso, ela lidou com pessoas diferentes (alunos, professores, gestores, auxiliares de escola) e participou ativamente de seus processos formativos, reinventando práticas usuais para o ensino de frações, indo ao encontro do que esclarece Arroyo (2010).

Em outras palavras, no caso em estudo a doçura do chocolate e labor da professora no preparo e na ministração da aula tornaram aquela experiência significativa para grande parte daqueles alunos, segundo seus relatos.

A presente pesquisa procurou evidenciar que as práticas pedagógicas desenvolvidas pelos professores em sala de aula devem ser conhecidas e estudadas, pois podem contribuir para o conjunto de estudos sobre o pensamento do professor, valorizando os saberes docentes e promovendo seu aprimoramento profissional. Segundo Tancredi $(2009$, p. 18):

\footnotetext{
[...] é preciso compartilhar. A docência, hoje, não pode mais ser uma atividade isolada, pois dificilmente alguém detém de uma vez e para sempre todo o conhecimento de que necessita para ensinar. A troca entre os pares - não apenas de atividades que podem ser usadas em sala de aula, mas de conhecimentos sistematizados e experiências - ajuda os professores a verem outros aspectos de uma situação, a colaborarem com a formação de outros professores, a cumprirem as propostas definidas junto a comunidade escolar.
}

Vale ressaltar que as práticas docentes são fundamentadas pelos conhecimentos adquiridos ao longo da vida, nos cursos de formação e em diversas situações. Não há dicotomia entre teoria e prática, há uma constante interação entre elas. Refletir sobre o que acontece nas salas de aula é um incentivo à pesquisa, à sistematização e à produção de conhecimentos que podem aperfeiçoar o trabalho docente em todos os níveis de ensino.

\section{REFERÊNCIAS}

ALUNOS DO 5. ANO. Entrevista. São Paulo, 21 outubro, 2012. 
ARROYO, Miguel González. Ofício de mestre. Imagens e autoimagens, 12 ed. Petrópolis, RJ: Vozes, 2010.

BOGDAN, Robert; BIKLEN, Sari Knopp. Investigação qualitativa em educação: uma introdução à teoria e aos métodos. Portugal: Porto Editora, 1994.

BRASIL. Ministério da Educação. Secretaria de Educação Fundamental. Parâmetros Curriculares Nacionais: Matemática ( $1^{\circ}$. e $2^{\circ}$. ciclos do ensino fundamental), v. 3. Brasília: MEC, 2000.

CALDEIRA, Anna Maria Salgueiro; ZAIDAN, Samira. Prática pedagógica. In: OLIVEIRA, Dalila Andrade; DUARTE, Adriana Cristina; VIEIRA, Lívia Maria Fraga (Org.). Dicionário: trabalho, profissão e condição docente. Belo Horizonte: GESTRADO/FaE/ UFMG, 2010, v. 1. Disponível em <http://www.gestrado.net.br/pdf/328.pdf $>$, acesso em $12 /$ julho/ 2016.

CORRADINI, Suely Nercessian; MIZUKAMI, Maria da Graça Nicoletti. Formação docente: o profissional da sociedade contemporânea. Estudo em formação docente 04. Revista Exitus, v. 1, nº. 1, jul./dez. 2011, p. 53-62. Disponível em:<http://www.ufopa.edu. $\mathrm{br} /$ revistaexitus/revistas/volume-i/artigos/formacao-docente-o-profissional-da-sociedade-contemporanea/view> Acesso em 20/jun./2013.

CUNHA, Maria Isabel da. O bom professor e sua prática, 10. ed. Campinas, SP: Papirus, 1989 (Coleção Magistério: Formação e Trabalho Pedagógico).

LIMA, José Maurício de Figueiredo. Iniciação ao conceito de fração e o desenvolvimento da conservação de quantidade. In: CARRAHER, Terezinha Nunes (Org.). Aprender pensando. Contribuições da Psicologia Cognitiva para a educação, 8. ed. Petrópolis, RJ: Vozes, 1993, p. 81-127.

MARCELO GARCÍA, Carlos. Formação de professores para uma mudança educativa. Portugal: Porto Editora, 1999 (Coleção Ciências da Educação século XXI).

MIZUKAMI, Maria da Graça Nicoletti. Aprendizagem da docência: algumas contribuições de L. S. Shulman. Revista Educação, ed. 2004, v. 29, nº 2. Disponível em:

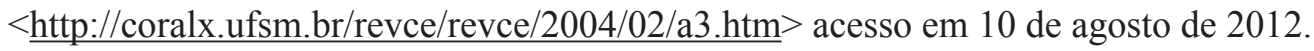

MIZUKAMI, Maria da Graça Nicoletti et al. Escola e aprendizagem da docência: processos de investigação e formação. São Carlos: EdUFSCar, 2010.

NUNES, Terezinha; BRYANT, Peter. Crianças fazendo Matemática. Porto Alegre: Artes Médicas, 1997.

ROMANATTO, Mauro Carlos; TANCREDI, Regina Maria Simões Puccinelli Ensinar e aprender Matemática: uma relação entre linguagens na formação e na atuação do professor. In: ASSOLINI, F. E. P.; LASTÓRIA, A. C. Diferentes linguagens no contexto escolar: questões conceituais e apontamentos metodológicos. Florianópolis: Insular, 2013, p. 93-105. 
SABRINA. Entrevista. São Paulo, 11 novembro, 2012.

SHULMAN, L. S. Those who understand: knowledge growth in teaching. Educational Researcher, v. 15, nº. 2, 1986, p. 4-14. Disponível em:

$<$ http://www.fisica.uniud.it/URDF/masterDidSciUD/materiali/pdf/Shulman_1986.pdf> Acesso em setembro 2012.

SHULMAN, L. S. Conhecimento e ensino: fundamentos para a nova reforma. Cadernos Cenpec| Nova série, [S.1.], v. 4, $\mathrm{n}^{\circ}$. 2, dezembro 2014. Disponível em: $<$ http://cadernos. cenpec.org.br/cadernos/index.php/cadernos/article/view/293>. Acesso em: 14 maio 2015.

SILVA, Elisabeth Ramos da; UYENO, Elzira Yoko; ABUD, Maria José Milharezi (Orgs.). Cognição, Afetividade e Linguagem. São Paulo: Cabral, 2007.

TANCREDI, Regina Maria Simões Puccinelli. Aprendizagem da docência e profissionalização: elementos de uma reflexão. São Carlos: EDUFSCar, 2009.

WILSON, Suzanne M.; SHULMAN, Lee S.; RICHERT, Anna Ershler. '150 ways' of knowing: representations of knowledge in teaching. In: CALDERHEAD, J. (Org.) Exploring teacher's thinking. Sussex: Holt, Rinehart \& Winston, 1987, p. 104-124.

\section{Dados das Autoras}

\section{Regina Maria Simões Puccinelli Tancredi}

Licenciada em Matemática pela Faculdade de Fisosofia, Ciências e Letras de Araraquara. Mestra em Educação pela Universidade Federal de São Carlos. Doutora em Educação pela Universidade Federal de São Carlos. São Carlos/SP - Brasil. retancredi@gmail.com

\section{Adriana Torquato Resende}

Graduada em Pedagogia pela Faculdade de Arujá. Mestra em Teologia pelo Centro Presbiteriano de Pós-graduação Andrew Jumper. Mestra em Educação, Arte e História da Cultura pela Universidade Presbiteriana Mackenzie. Doutora em Educação, Arte e História da Cultura. São Paulo/SP - Brasil. adrianatorquato27@gmail.com

Submetido em: 4-10-2016

Aceito em: 31-3-2017 